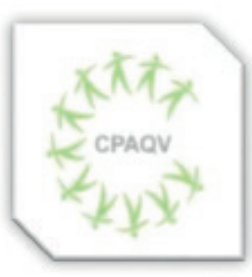

ISSN: 2178-7514

\title{
AVALIAÇÃO POSTURAL E DO QUADRO ÁLGICO EM APANHADORES DE LARANJA DO MUNICÍPIO DE CAPITÃO POÇO-PA
}

\section{Postural and algic evaluation in orange catchers in the municipality of Capitão Poço-PA}

Tereza Cristina dos Reis Ferreira ${ }^{1}$, Laura Enoy Barreto Soares ${ }^{2}$, Renata Cristina Moutinho Chermont ${ }^{2}$, Layse Caroline Felix Silva e Silva ${ }^{2}$, Gleydiene Alves de Sousa ${ }^{3}$, Carlos Augusto Lins Gomes ${ }^{3}$, André de Aguiar Santos Filho ${ }^{4}$, Wellington Pinheiro de Oliveira ${ }^{5}$, Keitty Anne Silva Neves ${ }^{6}$, Andréa Cristina Vale de Souza Pereira ${ }^{7}$

Vol. 13 | N. 2 | Ano 2021

\section{RESUMO}

Objetivo: Identificar as alterações posturais e do quadro álgico dos apanhadores de laranja residentes no município de Capitão Poço. Método: Foram avaliados 48 apanhadores de laranja do município de Capitão Poço, onde foram avaliados com auxílio de um simetógrafo as seguintes variáveis: ombros, cabeça, coluna cervical, dorsal, lombar, quadril, joelhos e pés, nos planos frontal, sagital e horizontal.Na análise do quadro álgico foi utilizado a EVA (Escala Visual Analógica) onde foi coletado o grau de dor e a sua localização. Resultados: Foram analisadas as prevalências das seguintes alterações posturais; hiperlordose cervical e anteriorização de cabeça 54,16\%, 72,92\% ombro esquerdo protraído, abdução de escápula direita 68,75\%, hipercifose torácica 48,83\%, hiperlordose $60,41 \%$, desnivelamento da pelve á esquerda 52,8\% e 45,83\% anteroversão, joelhos em valgo 35,42\% e 39,58\% hiperestendido do lado direito e pé direito normal 77,08\%. Quanto às algias, constatou-se que $87,5 \%$ dos avaliados relataram algum quadro álgico, no sexo feminino 16,6\% relataram EVA de $0,2,6$ e 7, já no sexo masculino $25 \%$ relataram EVA 5 . Conclusão: A quantidade de horas por dia e o tempo de prática de trabalho dos apanhadores de laranja levam os mesmos a possuir alterações posturais e quadro álgico.

Palavras-chave: Análise postural, alterações posturais, análise do quadro álgico, apanhadores de laranja.

\begin{abstract}
Objective: To identify the the change of the posture and painful picture of orange pickers living in the city of Captain Wells. Method: Was evaluated 48 orange collectors in the city of Captain Wells, were analyzed with a simetógrafo following variables: shoulders, head, cervical spine, dorsal spine, lumbar spine, hip, knees and feet, in frontal, sagittal and horizontal axis. in the analysis of pain was used VAS (Visual Analogue Scale) was collected where the degree of pain and its location. Results: Was analyzed a prevalence of the following postural changes, cervical hyperlordosis and forward head $54.16 \%, 72.92 \%$ left shoulder protracted, abduction of the right scapula $68.75 \%, 48.83 \%$ thoracic kyphosis, hyperlordosis $60.41 \%$ depression of the left pelvis $52.8 \%$ and $45.83 \%$ anteversion, knee valgus $35.42 \%$ and $39.58 \%$ on the right and hyperextended right foot normal $77.08 \%$. As for the pains, it was found that $87.5 \%$ of the sample reported some pain symptoms in females $16.6 \%$ reported VAS of $0,2,6$ and 7 , as in males $25 \%$ reported EVA 5. Conclusion: The amount of hours per day and practice time working the orange pickers take them to have postural changes and pain.
\end{abstract}

Keywords: postural analysis, postural changes, analysis of pain, orange pickers.

Autor de correspondência

1- Fisioterapeuta. Dra em Ciências da Reabilitação (UNINOVE). Docente da Universidade do Estado do Pará (UEPA)

2- Fisioterapeuta. Graduada pelo Centro Universitário do Pará (CESUPA)

3- Discentes do Curso de Fisioterapia da Faculdade Paraense de Ensino (FAPEN)

4- Discente do Curso de Fisioterapia da Universidade do Estado do Pará (UEPA)

5- Fisioterapeuta. Mestre em genética e biologia molecular (UFPA). Docente do Centro Universitário do Pará (CESUPA)

6- Fisioterapeuta. Mestre em Epidemiologia e Vigilância em Saúde (UFPA). Docente da Faculdade Cosmopolita.

7- Fisioterapeuta. Especialista Saúde e Desporto. Docente da Faculdade Paraense de Ensino (FAPEN)

Tereza Cristina dos Reis Ferreira - tereza.reis@uepa.br 


\section{INTRODUÇÃO}

O sistema agroindustrial da laranja é sem dúvida um caso de sucesso no agronegócio brasileiro. Afinal, é um produto que atende cerca de $81 \%$ das transações internacionais, fato que coloca o Brasil na primeira posição do ranking dos maiores exportadores de suco de laranja do mundo, correspondendo a 1,8\% da pauta brasileira de exportação e a um terço de toda a produção mundial, com seus quase 9 milhões de toneladas por ano ${ }^{1}$

A laranja pêra é cultivada em maior escala no Norte do país. A árvore de porte médio possui altura aos 12 anos de idade em torno de $4 \mathrm{~m}$, copa ereta, circunferência em torno de $15 \mathrm{~m}$ e diâmetro do tronco (a $30 \mathrm{~cm}$ do solo) de $17 \mathrm{~cm}^{2}$.

Embora a colheita mecanizada tenha se destacado em muitos países, no Brasil, ainda se utiliza a colheita manual, visando a redução das perdas e danos aos frutos ${ }^{3}$.

$\mathrm{Na}$ agricultura, o trabalho pesado faz parte da rotina diária, pois os trabalhadores lidam com o manuseio de cargas, especialmente com o levantamento das mesmas. Os autores também ressaltam que o principal problema não é tanto as exigências dos músculos, mas sim o desgaste dos discos intervertebrais. As doenças da coluna provocam dores e limitam a mobilidade e a vitalidade das pessoas, levam a uma ausência prolongada do trabalho e são uma das principais causas de invalidez prematura ${ }^{4}$.

A citricultura é um trabalho extenuante, que exige alto gasto de energia física por envolver vários músculos e posturas desconfortáveis ${ }^{5}$.

A colheita de citrus é uma tarefa relativamente complexa, que envolve, inicialmente, uma procura e identificação visual, seguido da decisão se está no ponto de ser colhida. Para a coleta é feito um movimento do braço em direção à fruta, segue-se o agarramento, a quebra da haste e a colocação da mesma em recipientes como caixas, cestos ou sacolas. No decorrer desta tarefa, o agricultor precisa olhar para cima, inclinando a cabeça para trás e erguer os braços para cima. Para alcançar as frutas mais baixas, o trabalhador precisa inclinar-se, flexionando a coluna, além de realizar o trabalho estático com um dos braços, segurando o recipiente contento as frutas colhidas. O movimento dos braços para alcançar as frutas provoca também uma sobrecarga nos ombros ${ }^{6}$.

Desta forma, justificam-se os esforços da ergonomia em reduzir os danos à saúde dos trabalhadores, a fadiga, o estresse, buscando melhores condições de trabalho, adequação dos instrumentos ao homem e ao trabalho, proporcionando segurança, conforto, o que aumentará a satisfação no trabalho, e conseqüentemente, terá um significativo 
aumento da produtividade ${ }^{5}$.

Este trabalho se justifica pela carência de literatura sobre a importância da realização de novos estudos sobre os trabalhadores temporários e sua inserção na moderna (e cada vez mais mecanizada) agricultura de larga escala, desvendando suas especificidades e contribuindo para o seu entendimento.

\section{MÉTODOS}

Todos os apanhadores de laranja da presente pesquisa foram estudados respeitando as normas de Pesquisa Envolvendo Seres Humanos do Conselho Nacional de Saúde, após o aceite da orientadora e do proprietário do Rancho Alagoas , após aprovação do Comitê de ética e Pesquisa do Centro Universitário do Pará sob o número 01819012.0.0000.5169, e pelos apanhadores estudados por meio de termo de consentimento livre e esclarecido (TCLE).

O tipo de estudo realizado nesta pesquisa foi prospectivo observacional. A amostra foi constituída por 48 apanhadores de laranja do Rancho Alagoas, localizado no município de Capitão Poço, no mês de Maio de 2012. Os critérios de inclusão foram: apanhadores de laranja de ambos os sexos, com idade acima de 20 anos. E como critérios de exclusão: apanhadores menores de 20 anos.

A pesquisa foi realizada em espaço cedido pelo proprietário do Rancho Alagoas, sendo aqueles que aceitaram participar da pesquisa por livre e espontânea vontade, e respeitando os critérios de inclusão e exclusão, receberam explicação minuciosa sobre os objetivos, métodos, riscos e benefícios da pesquisa, e cessada todas as dúvidas os participantes receberam o TCLE para a leitura, após a mesma os participantes assinaram voluntariamente o TCLE concordando com os termos deste estudo.

Posteriormente, foram avaliados no local pelas avaliadoras. Os pacientes foram avaliados vestindo shorts para os apanhadores e top e short para as apanhadoras; para facilitar a visualização dos segmentos corporais no plano frontal, sagital e horizontal. Os dados coletados foram anotados em ficha de avaliação postural adaptada da ficha de avaliação postural do livro cadeias musculares (MARQUES, 2005). As variáveis deste estudo foram: cabeça, clavículas, ombros, escápulas, coluna cervical, dorsal, lombar, pelve, joelhos e pés, que foram avaliados por meio do simetógrafo impresso pelas autoras do projeto de tamanho aproximadamente de $1.50 \mathrm{~m}$ x $1.20 \mathrm{~m}$, riscada na horizontal e vertical formando quadrados de $5 \mathrm{~cm}$ de lado que foi fixado numa sala reservada para a avaliação na casa principal do Rancho, foram identificados os desvios posturais mais evidentes para visualizar os apanhadores nas 
posições anterior, posterior e lateral a direita

e esquerda, sendo os dados anotados na ficha própria.

Os pacientes foram submetidos também à Escala Visual Analógicos da Dor (EVA) durante a avaliação, a qual se apresenta contendo em um dos extremos a expressão "sem dor ou dor leve" (representada pela cor azul) e na extremidade oposta a expressão "dor intensa" (representada pela cor vermelha) e uma variação numérica de zero a 10 , sendo considerada maior o valor indicado pelo indivíduo quanto mais próximo de 10 e menor quanto mais próximo de zero (JENSEN, 1992).

A identificação do local da dor foi feita a partir da identificação manual do local de queixa do paciente.

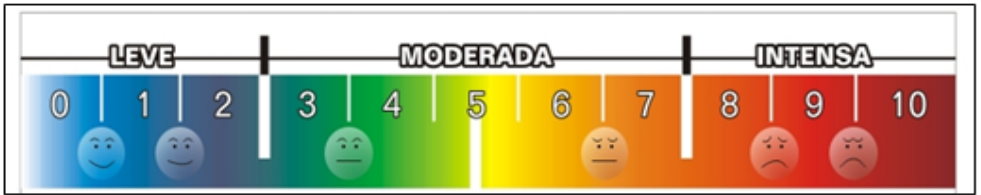

Figura 3: Escala Visual Analógica de dor

Fonte: http:/hmw hen riquecarneiro.com.br/dor-de-cabecalescala-an alogica-visual-de-dor

Os dados obtidos nas avaliações foram digitados em um banco para a execução da análise estatística dos mesmos. De acordo com a natureza das variáveis, foi aplicada análise estatística descritiva, sendo informados os valores percentuais dos dados analisados. O banco de dados, bem como as tabelas e os gráficos foram construídos no Microsoft EXCEL 2007 e a utilização do software BioEstat 5.0.

\section{RESULTADOS}

Neste estudo foram avaliados 48 apanhadores de laranja do município de Capitão Poço, sendo que 36 eram do sexo masculino e 12 do sexo feminino. Com média de idade para o sexo masculino de $32,44 \%$ anos e a média para o sexo feminino de $37,5 \%$ anos. A média de dias de trabalho nos apanhadores do sexo masculino foram de 4 dias por semana e média de $6,7 \%$ horas por dia. A média de dias de trabalho nos apanhadores do sexo feminino foi de 3,6 dias por semana e média de 6,09 horas por dia.

A distribuição quanto às algias, constatou-se que $87,5 \%$ da amostra relatou algum quadro álgico, sendo $66,6 \%$ do sexo masculino e 20,83\% do sexo feminino. Quanto à maior incidência de dor, pôde-se observar que no sexo feminino, $16,6 \%$ relataram EVA de 0, 2, 6 e 7. Já no sexo masculino, 25\% relataram EVA 5 (TABELA 1). 
Tabela 1 - Distribuição dos apanhadores $(\mathrm{N}=48)$ de acordo com a escala visual an alógica apresentado

\begin{tabular}{ccc}
\hline ESCALA VISUAL ANALÓGICA & FEMININO & MASCULINO \\
\hline $\mathbf{0}$ & 2 & 4 \\
1 & 0 & 1 \\
2 & 1 & 2 \\
3 & 2 & 3 \\
4 & 1 & 6 \\
5 & 1 & 9 \\
6 & 2 & 2 \\
7 & 2 & 7 \\
$\mathbf{8}$ & 1 & 1 \\
9 & 0 & 1 \\
\hline TOTAL & & 36 \\
\hline Fonte: Protocolo de pesquisa, 2012 & 12 &
\end{tabular}

Em relação à correlação localização da dor e o nível de dor para os apanhadores do sexo feminino obtiveram-se os seguintes dados: $\mathrm{Na}$ região cervical o nível de dor foi de EVA 4 para uma apanhadora, para a região cervical e torácica obteve-se EVA 2 para uma apanhadora, já nas regiões cervical, torácica, lombar e membros inferiores (MMII), a EVA foi de 7 para uma apanhadora. Em joelhos e lombar, a EVA de uma apanhadora foi de 3. Em joelhos, cervical e lombar, obteve-se EVA 5 para uma apanhadora, e para a região da lombar, uma apanhadora apresentou EVA 3. Duas das apanhadoras não relataram nenhuma dor. Nas regiões torácica e lombar, duas apanhadoras apresentaram EVA 6 e uma EVA 8, já nas regiões torácica, lombar e cervical, uma apanhadora apresentou EVA 7 (TABELA 2).

Tabela 2 - Distribuiçäo dos apanhadores do sexo feminino ( $N=12)$ de acordo com a escala visual an alógica e a localizaça̋o da dor apresentado.

\begin{tabular}{|c|c|c|c|c|c|c|c|c|c|}
\hline \multirow{2}{*}{$\begin{array}{l}\text { SEXO } \\
\text { LOCALIZACÄO/EVA }\end{array}$} & \multicolumn{8}{|c|}{ FEMININO } & \multirow{2}{*}{ TOTAL } \\
\hline & 0 & 2 & 3 & 4 & 5 & 6 & 7 & 8 & \\
\hline Cervical & 0 & 0 & 0 & 1 & 0 & 0 & 0 & 0 & 1 \\
\hline \multirow{2}{*}{$\begin{array}{l}\text { Cervical e torácica } \\
\text { Cervical, torácica, } \\
\text { lombar e Mitill }\end{array}$} & 0 & 1 & 0 & 0 & 0 & 0 & 0 & 0 & 1 \\
\hline & 0 & 0 & 0 & 0 & 0 & 0 & 1 & 0 & 1 \\
\hline \multirow{2}{*}{$\begin{array}{l}\text { Joelhos e lombar } \\
\text { Joelhos, cervical e } \\
\text { lombar }\end{array}$} & 0 & 0 & 1 & 0 & 0 & 0 & 0 & 0 & 1 \\
\hline & 0 & 0 & 0 & 0 & 1 & 0 & 0 & 0 & 1 \\
\hline Lombar & 0 & 0 & 1 & 0 & 0 & 0 & 0 & 0 & 1 \\
\hline Sem dor & 2 & 0 & 0 & 0 & 0 & 0 & 0 & 0 & 2 \\
\hline \multirow{2}{*}{$\begin{array}{l}\text { Torácica e lombar } \\
\text { Torácica, lombar e } \\
\text { cervical }\end{array}$} & 0 & 0 & 0 & 0 & 0 & 2 & 0 & 1 & 3 \\
\hline & 0 & 0 & 0 & 0 & 0 & 0 & 1 & 0 & 1 \\
\hline Total & 2 & 1 & 2 & 1 & 1 & 2 & 2 & 1 & 12 \\
\hline
\end{tabular}


Em relação à correlação localização da dor e o nível de dor para os apanhadores do sexo masculino obtiveram-se os seguintes dados: Nas regiões cervical e torácica, o nível de dor foi de EVA 4 para um apanhador e de EVA 7 para outro colaborador, para a região cervical, torácica e lombar obteve -se EVA 4 para um apanhador e de EVA 7 para outro colaborador. Um apanhador relatou EVA 7 na lombar, nas regiões de joelhos, lombar e ombros, um apanhador apresentou EVA 2. Na lombar, dois apanhadores relataram EVA 3, dois relataram EVA 4, outros dois colaboradores EVA 5, um apanhador apresentou EVA 6, um apanhador obteve EVA 7 e um colaborador apresentou EVA 8. Na lombar e no ombro direito, um apanhador obteve EVA 5, em ombro direito, um colaborador apresentou EVA 9, em ombro direito e cervical um apanhador obteve EVA 4, em ombros e lombar, um apanhador apresentou EVA 7. Nas regiões de ombros, coluna lombar e torácica, um apanhador apresentou EVA 7. Quatro apanhadores apresentaram-se sem dor. Na região torácica, um apanhador relatou EVA 2 e três apanhadores relataram EVA 5. Nas regiões torácica e lombar, um apanhador apresentou EVA 3, dois apresentaram EVA 5 e um relatou EVA 7. Nas regiões torácica, lombar e cotovelo direito, um apanhador obteve EVA 1, em coluna torácica, lombar e ombro, um apanhador apresentou EVA 4 e nas regiões de torácica, lombar e cervical, um apanhador obteve EVA 6 (TABELA 3).

Tabela 3 - Distribuição dos apanhadores do sexo masculino ( $\mathrm{N}=36$ ) de acordo com a escala visual an alógica e a localizaçẫo da dor apresentado.

\begin{tabular}{|c|c|c|c|c|c|c|c|c|c|c|c|}
\hline \multicolumn{5}{|l|}{ SEXO } & \multicolumn{6}{|c|}{ MASCULINO } & \multirow{2}{*}{ TOTAL } \\
\hline LOCALIZACÄO/EVA & 0 & 1 & 2 & 3 & 4 & 5 & 6 & 7 & 8 & 9 & \\
\hline \multirow{2}{*}{$\begin{array}{l}\text { Cenvical e torácica } \\
\text { Cervical, torácica e } \\
\text { lombar }\end{array}$} & 0 & 0 & 0 & 0 & 1 & 0 & 0 & 1 & 0 & 0 & 2 \\
\hline & 0 & 0 & 0 & 0 & 1 & 0 & 0 & 1 & 0 & 0 & 2 \\
\hline \multirow{3}{*}{$\begin{array}{l}\text { Dor lombar } \\
\text { Joelhos, lombare } \\
\text { ombros } \\
\text { Joelhos, ombrose } \\
\text { lombar }\end{array}$} & 0 & 0 & 0 & 0 & 0 & 0 & 0 & 1 & 0 & 0 & 1 \\
\hline & 0 & 0 & 1 & 0 & 0 & 0 & 0 & 0 & 0 & 0 & 1 \\
\hline & 0 & 0 & 0 & 0 & 0 & 1 & 0 & 0 & 0 & 0 & 1 \\
\hline Lombar & 0 & 0 & 0 & 2 & 2 & 2 & 1 & 1 & 1 & 0 & 9 \\
\hline Lombar e ombro Direito & 0 & 0 & 0 & 0 & 0 & 1 & 0 & 0 & 0 & 0 & 1 \\
\hline Ombro direito & 0 & 0 & 0 & 0 & 0 & 0 & 0 & 0 & 0 & 1 & 1 \\
\hline Ombro Direito e cervical & 0 & 0 & 0 & 0 & 1 & 0 & 0 & 0 & 0 & 0 & 1 \\
\hline \multirow{2}{*}{$\begin{array}{l}\text { Ombros e lombar } \\
\text { Ombros, coluna lombare } \\
\text { torácica }\end{array}$} & 0 & 0 & 0 & 0 & 0 & 0 & 0 & 1 & 0 & 0 & 1 \\
\hline & 0 & 0 & 0 & 0 & 0 & 0 & 0 & 1 & 0 & 0 & 1 \\
\hline Sem dor & 4 & 0 & 0 & 0 & 0 & 0 & 0 & 0 & 0 & 0 & 4 \\
\hline Torácica & 0 & 0 & 1 & 0 & 0 & 3 & 0 & 0 & 0 & 0 & 4 \\
\hline \multirow{2}{*}{$\begin{array}{l}\text { Torácica e lombar } \\
\text { Torácica lombar e } \\
\text { cotovelo Direito }\end{array}$} & 0 & 0 & 0 & 1 & 0 & 2 & 0 & 1 & 0 & 0 & 4 \\
\hline & 0 & 1 & 0 & 0 & 0 & 0 & 0 & 0 & 0 & 0 & 1 \\
\hline \multirow{2}{*}{$\begin{array}{l}\text { Torácica, lombar e ombro } \\
\text { Torácica, lombar, } \\
\text { cervical. }\end{array}$} & 0 & 0 & 0 & 0 & 1 & 0 & 0 & 0 & 0 & 0 & 1 \\
\hline & 0 & 0 & 0 & 0 & 0 & 0 & 1 & 0 & 0 & 0 & 1 \\
\hline Total qeral & 4 & 1 & 2 & 3 & 6 & 9 & 2 & 7 & 1 & 1 & 36 \\
\hline
\end{tabular}

Fonte: Protocolo de pesquisa, 2012. 
A seguir apresentam-se as variáveis dedos, 58,33\% (28) apresentavam-se normais; referentes a analise postural. 39,5\% (19) com o hálux valgo e 2.08\% (01)

Em relação aos dedos do pé com analise fletidos (TABELA 4). bilateral evidenciou-se que em relação aos

\begin{tabular}{lcc}
\multicolumn{2}{c}{ Tabela 4 - Variaçôes posturais dos dedos do pé (N=48), de acordo com o segmento avaliado. } \\
\multicolumn{1}{c}{ SEGMENTO } & N & $\%$ \\
\hline DEDOS DO PÉ & 1 & 2,08 \\
Fletidos & 19 & 39,5 \\
HáluxValgo & 28 & 58,33 \\
Normal &
\end{tabular}

Quanto à postura do pé observou-se que $72,92 \%$ (35) dos indivíduos apresentam pé direito normal 77,08\% (37) pé esquerdo normal; 8,33\% (04) apresentam pé cavo direito e 8,33\% (04) pé cavo a esquerdo; No entanto, $18,75 \%$ (09) tiveram pé plano direito e 14,58\% (07) pé plano esquerdo. Em relação ao retropé, 31,25\% (15) apresentaram retropé direito valgo, 25\% (12) retropé esquerdo valgo, $8,33 \%$ (04) retropé varo em ambos os lados. Os trabalhadores que possuíram retropé normal foram $60,42 \%$ (29) para o lado direto e 66,67\% (32) para o lado esquerdo (TABELA 5).
Quanto aos joelhos dos apanhadores, encontrou-se: $35,42 \%$ (17) valgo do lado direito e esquerdo e 31,25\% (15) varo em ambos os lados. Em relação a Joelhos fletidos, 4,17\% (02) apresentaram joelhos fletidos do lado direito, sendo que, 2,08\% (01) fletidos do lado esquerdo. Verificou-se que 39,58\% (19) dos apanhadores apresentaram joelho hiperestendido do lado direito e 31,25\% (15) do lado esquerdo. Quanto à rotação de joelhos, $10,42 \%$ (05) apresentaram rotacionados à direita e 25\% (12) rotacionados à esquerda (TABELA 5).

Tabela 5 - Variaçőes postu rais do pé, retropé e joelhos ( $N=48)$, de acordo com o segmento avaliado.

\begin{tabular}{|c|c|c|c|c|}
\hline SEGMENTO & N Direito & N Esquerdo & $\%$ Direito & $\%$ Esquerdo \\
\hline \multicolumn{5}{|l|}{$\mathrm{PE}$} \\
\hline Normal & 35 & 37 & 72,92 & 77,08 \\
\hline Cavo & 4 & 4 & 8,33 & 8,33 \\
\hline Plano & 9 & 7 & 18,75 & 14,58 \\
\hline \multicolumn{5}{|l|}{ RETROPE் } \\
\hline Valgo & 15 & 12 & 31,25 & 25 \\
\hline Varo & 4 & 4 & 8,33 & 8,33 \\
\hline Normal & 29 & 32 & 60,42 & 66,67 \\
\hline \multicolumn{5}{|l|}{ JOELHO } \\
\hline Valgo & 17 & 17 & 35,42 & 35,42 \\
\hline Varo & 15 & 15 & 31,25 & 31,25 \\
\hline Fletido & 2 & 1 & 4,17 & 2,08 \\
\hline Hiperestendido & 19 & 15 & 39,58 & 31,25 \\
\hline Rotaçẩo & 5 & 12 & 10,42 & 25 \\
\hline
\end{tabular}

Fonte: Protocolo de pesquisa, 2012 
Em relação à postura de pelve e coluna lombar evidenciou-se que para a pelve no plano frontal, 41,6\% (20) apresentaram desnivelamento para o lado direito, 52,8\% (25) desnivelamento para o lado esquerdo e 6,25\% (03) sem desnivelamento. Já no plano sagital, 45,83\% (22) apresentaram anteroversão, 37,5 (18) retroversão e 16,66\% (08) normais (TABELA 6).
Quanto às variáveis encontradas para a coluna lombar, encontrou-se: 22,91\% (11) com lordose, 60,41\% (29) com hiperlordose, 16,66\% (08) com retificação. 45,83\% (22) apresentaram cifose torácica. Nas variáveis da clavícula, foram encontrados 25\% (12) oblíquas, 4,16\% (02) horizontalizadas e 70,83\% (34) normais (TABELA 6).

\begin{tabular}{|c|c|c|}
\hline SEGMENTO & $\mathbf{N}$ & $\%$ \\
\hline \multicolumn{3}{|l|}{ PELVE PLANO FRONTAL } \\
\hline Desnivelamento $D$ & 20 & 41,6 \\
\hline Desnivelamento $\mathrm{E}$ & 25 & 52,8 \\
\hline Nenhum & 3 & 6,25 \\
\hline \multicolumn{3}{|l|}{ PELVE PLANO SAGITAL } \\
\hline Anteroversão & 22 & 45,83 \\
\hline Retroversão & 18 & 37.5 \\
\hline Normal & 8 & 16,66 \\
\hline \multicolumn{3}{|l|}{ LOMBAR } \\
\hline Lordose & 11 & 22,91 \\
\hline Hiperlordose & 29 & 60,41 \\
\hline Retificação & 8 & 16,66 \\
\hline CIFOSE TORÁCICA & 22 & 45,83 \\
\hline \multicolumn{3}{|l|}{ CLAVÍCULA } \\
\hline Oblíqua & 12 & 25 \\
\hline Horizontalizada & 2 & 4,16 \\
\hline Normal & 34 & 70,83 \\
\hline
\end{tabular}

Quanto à postura de tronco dos apanhadores de laranja, 22,92\% apresentaram escoliose cervical à direita, 29,17\% (14) à esquerda, 45,83\% (22) apresentaram escoliose torácica à direita, 33.33\% (16) à esquerda, 39,58\% (19) apresentaram escoliose lombar à direita e 43,75\% (21) à esquerda. $\mathrm{Na}$ escápula, 43,75\% (21) apresentaram elevação de escápula direita, 47,92\% (23) esquerda, 68,75\% (33) apresentaram abdução de escápula direita, 66,67\% (32) esquerda, 2,08\% (01) com adução de escápula direita e esquerda, 8,33\% com depressão e rotação em ambos os lados. (TABELA 7).

Nas informações coletadas sobre os ombros dos apanhadores, foi visto que 70,83\% (34) tinham o ombro direito protraído, 72,92\% (35) ombro esquerdo protraído, 35,42\% (17) apresentavam ombro direito elevado, 56,25\% (27) ombro esquerdo elevado, 20,83\% (10) tiveram ombro direito com desnivelamento e $14,58 \%$ (07) ombro esquerdo com desnivelamento (TABELA 7). 
Tabela 7 - Variações posturais do tron co, escápula e ombro ( $N=48)$, de acordo com o segmento avaliado

\begin{tabular}{|c|c|c|c|c|}
\hline SEGMENTO & N Direito & N Esquerdo & $\%$ Direito & $\%$ Esquerdo \\
\hline \multicolumn{5}{|l|}{ TRONCO } \\
\hline Escoliose Cervical & 11 & 14 & 22,92 & 29,17 \\
\hline Escoliose Torácica & 22 & 16 & 45,83 & 33,33 \\
\hline Escoliose Lombar & 19 & 21 & 39,58 & 43,75 \\
\hline \multicolumn{5}{|l|}{ ESCÄPULA } \\
\hline Elevação da escápula & 21 & 23 & 43,75 & 47,92 \\
\hline Abduçã̃o da escápula & 33 & 32 & 68,75 & 66,67 \\
\hline Aduçẫo da escápula & 1 & 1 & 2,08 & 2,08 \\
\hline Depressẫo e Rotação & 4 & 4 & 8,33 & 8,33 \\
\hline \multicolumn{5}{|l|}{ OMBRO } \\
\hline Protraídos & 34 & 35 & 70,83 & 72,92 \\
\hline Elevados & 17 & 27 & 35,42 & 56,25 \\
\hline Desnivelamento & 10 & 7 & 20,83 & 14,58 \\
\hline
\end{tabular}

Fonte: Protocolo de pesquisa, 2012.

Em relação às variáveis posturais da se que 35,41\% (17) tinham a cabeça inclinada cervical, foram encontradas: 20,83\% (10) para a esquerda, 20,83\% (10) apresentavam a alinhadas, 54,16\% (26) com hiperlordose e cabeça sem alterações e 43,75\% (21) tinham a anteriorização, 25\% (12) retificada. Em relação cabeça inclinada para a direita (TABELA 8). à cabeça dos apanhadores de laranja, analisou-

Tabela 8 - Variaçôes posturais da cervical e da cabeça $(N=48)$, de acordo com o segmento avaliado.

\begin{tabular}{lcc}
\multicolumn{1}{c}{ SEGMENTO } & N & $\%$ \\
\hline \multicolumn{1}{c}{ CERVICAL } & & \\
Alinhada & 10 & 20,83 \\
hiperlordose e anteriorizaçẳo & 26 & 54,16 \\
Retificada & 12 & 25 \\
\multicolumn{1}{c}{ CABEÇA } & & \\
Normal & 10 & 20,83 \\
Inclinaçẩo para a E & 17 & 35,41 \\
Inclinaçẫo para a D & 21 & 43,75 \\
\hline
\end{tabular}

Fonte: Protocolo de pesquisa, 2012.

\section{DISCUSSÃO}

Neste estudo foram avaliados 48 apanhadores de laranja do município de Capitão Poço. Não se podem estabelecer quantos apanhadores de laranja existem de fato no município, visto que na cidade não existe uma Associação de apanhadores de laranja, desta forma foi selecionado um local para a execução deste estudo.

$\mathrm{Na}$ literatura poucos são os estudos relacionados aos apanhadores de laranja, e até o momento, poucos são os estudos que correlacionam a atividade de apanhar laranja com alterações posturais e com o quadro álgico. 
A posição de pé durante a jornada de trabalho é necessária para os apanhadores de laranja. Onde os apanhadores levam a escada até a laranjeira, sobem a mesma, com a sacola coletora sob o tronco e lá permanecem durante um tempo prolongado até as sacolas coletoras ficarem cheias de laranjas. E então os apanhadores descem as escadas e esvaziam as sacolas coletoras em caixas plásticas.

Segundo Veronesi ${ }^{7}$ o trabalho na postura de pé favorece uma sobrecarga para os MMII e a coluna lombar. De acordo com Dul e Weerdmeester ${ }^{8}$ passar muito tempo na posição de pé, provoca fadiga nas costas e pernas. Um estresse adicional pode aparecer quando o tronco fica inclinado, provocando dores no pescoço e nas costas. Além disso, trabalhar com os braços para cima, sem apoio, provoca dores nos ombros.

Segundo IIDA $^{6}$, a posição parada em pé, é altamente fatigante porque exige muito trabalho estático da musculatura envolvida para manter essa posição, pois na realidade o corpo não fica totalmente estático, mas oscilando, exigindo freqüentes reposicionamentos, dificultando a realização de movimentos precisos. Quando se permanece durante muito tempo na mesma postura, com a cabeça inclinada para frente é provocada uma fadiga da musculatura das costas onde o tipo mais simples ocorre com a dor na lombar.

A posição de pé sobre os degraus da escada oferece uma superfície instável e bem menor que o apoio podal do trabalhador, exigindo maior trabalho da musculatura envolvida para poder manter o equilíbrio.

IIDA $^{6}$ reforça sobre a postura com a cabeça inclinada para frente que é utilizada por apanhadores de laranja para facilitar a visualização e identificação do fruto. Pois essa postura provoca fadiga rápida dos músculos do pescoço e do ombro, as dores no pescoço começam a aparecer quando a inclinação da cabeça, em relação a vertical, for maior que $30^{\circ}$.

As forças que atuam sobre a coluna vertebral incluem peso corporal, tensão nos ligamentos vertebrais, tensão nos músculos circundantes, pressão intra-abdominal e quaisquer cargas externas aplicadas. Quando o corpo se encontra em posição ereta, a principal forma de carga que atua sobre a coluna vertebral é a axial. Nessa posição, o peso corporal, o peso de qualquer carga mantida nas mãos e a tensão nos ligamentos e músculos circunjacentes contribuem para a compressão vertebral ${ }^{9}$,

Um dos principais problemas que os trabalhadores que manuseiam e movimentam cargas pesadas enfrentam é a dor lombar. Estudos citam que cerca de $80 \%$ da população mundial sofre ou sofrerá de crise de dor lombar em algum momento da vida ativa ${ }^{10}$.

Segundo Fanhani et $\mathrm{al}^{11}$ todos os agricultores apresentam algum tipo de dor. A dor é o principal sintoma na maioria dos agricultores e a principal causa de afastamento. 
Estudos semelhantes revelam que o maior comprometimento está relacionado com a coluna lombar. A lombalgia é citada como a causa mais freqüente de diminuição da capacidade no trabalho, de forma temporária e permanente, estando em segundo lugar nos afastamentos do trabalho.

Uma coluna pode ter um alinhamento defeituoso acentuado, como uma hiperlordose sem retração dos músculos lombares. O movimento pode não causar uma distensão, mas ficar em pé por certo período de tempo pode dar origem à dor. A sobrecarga compressiva que resulta do mau alinhamento, quando acentuada ou constante, pode provocar sintomas dolorosos. O defeito é geralmente associado com fraqueza dos músculos abdominais. O surgimento dos sintomas é geralmente gradual em vez de agudo, e os sintomas geralmente permanecem mais ou menos crônicos. A dor é menor se a pessoa está ativa do que se a pessoa está em pé parada e é aliviada pela posição recumbente ou parada ${ }^{9}$.

Posturas torcidas do tronco causam tensões indesejáveis nas vértebras. Os discos elásticos que existem entre as vértebras são pressionados, e as articulações e músculos que existem nos dois lados da coluna vertebral são submetidos a cargas assimétricas, que são prejudiciais $^{8}$.

De acordo com todos os trabalhadores, o trabalho de colheita no início é pesado, mas depois se acostuma, e que é um trabalho como todos os outros, mas que se sentem cansados durante sua realização, principalmente, ao final do dia, por ficar o dia todo subindo e descendo a escada, carregando peso ${ }^{5}$.

A tensão contínua de certos músculos do corpo, como resultado de uma postura prolongada ou de movimentos repetitivos, provoca fadigas musculares localizadas, resultando em desconforto e queda do desempenho. Quanto maior o esforço muscular, menor se torna o tempo suportável. A maioria das pessoas não consegue manter o esforço muscular máximo além de alguns segundos 8 .

Nenhuma postura ou movimento repetitivo deve ser mantido por um longo período. As posturas prolongadas e os movimentos repetitivos são muito fatigantes. A longo prazo, podem produzir lesões nos músculos e articulações. Isso pode ser prevenido com uma alternância das posturas ou tarefas 8 .

\section{CONCLUSÃO}

Durante a pesquisa de campo deste trabalho evidenciou-se nas avaliações posturais de 48 apanhadores de laranja, sendo que 36 foram do sexo masculino na faixa etária média 32,44 anos no qual já estão nesta atividade a cerca de 8,5 anos e trabalham em média 6,7 horas por dia, e 12 do sexo feminino na faixa etária média de 37,5 anos no qual já estão nesta atividade a cerca de 10,08 anos e 
trabalham em média 6,09 horas por dia, que apresentaram as seguintes alterações posturais: joelhos $35,42 \%$ valgo e $31,25 \%$ varo. $\mathrm{Na}$ pelve no plano frontal, 41,6\% apresentaram desnivelamento para o lado direito e 52,8\% desnivelamento para o lado esquerdo, e no plano sagital, 45,83\% apresentaram anteroversão, 37,5 obtiveram retroversão. $\mathrm{Na}$ coluna lombar 60,41\% apresentaram-se com hiperlordose, 39,58\% apresentaram escoliose lombar e 16,66\% com retificação. $\mathrm{Na}$ coluna torácica $45,83 \%$ apresentaram cifose torácica e 45,83\% apresentaram escoliose torácica à direita, $33.33 \%$ à esquerda.

$\mathrm{Na}$ escápula, 43,75\% apresentaram elevação de escápula direita, 47,92\% esquerda, 68,75\% apresentaram abdução de escápula direita, 66,67\% esquerda, nos ombros 70,83\% tinham o ombro direito protraído, 72,92\% ombro esquerdo protraído, na coluna cervical $54 \%$ com hiperlordose e anteriorização.

$\mathrm{Na}$ avaliação do quadro álgico evidenciou-se que $87,5 \%$ da amostra relatou algum quadro álgico, sendo $66,6 \%$ foram do sexo masculino e $20,83 \%$ do sexo feminino. Quanto à maior incidência de dor, pôde-se observarque no sexo feminino, $16,6 \%$ relataram EVA de 0, 2, 6 e 7. Já no sexo masculino, 25\% relataram EVA 5.

O controle postural depende de uma série de estruturas corporais de forma alinhada como: pés, pernas e joelhos, pelve, coluna vertebral, músculos abdominais, cintura escapular, tórax e cabeça. Portanto, é fundamental se ter uma postura correta, pois dessa maneira teremos boas respostas aos estímulos internos e externos, adequando o funcionamento dos sistemas neuropsicomotor, cardiocirculatório e respiratório, melhorando a qualidade de vida e prevenindo o estresse.

$\mathrm{Na}$ localização do quadro álgico evidenciou-se que no sexo masculino $16,6 \%$ apresentaram queixas de dor na cervical, $55,5 \%$ na torácica, 58,3\% na lombar, 5,5\% nos joelhos, $22,2 \%$ nos ombros, $2,7 \%$ no cotovelo e 11,1 \% não apresentaram queixas de dor. No sexo feminino evidenciou-se as principais queixas de dor em 41,6\% em cervical, 50\% em torácica, 75\% em lombar, 16,6\% em joelhos $8,3 \%$ em MMII e 16,6\% não relataram queixas de quadro álgico.

Desta forma, novos estudos são necessários para que se avalie a correlação das alterações posturais e o quadro álgico apresentados por estes trabalhadores e a execução das tarefas são necessários, para minimizar viés de padrões adotados no diaa-dia que possam interferir nos achados, bem como dados para fundamentar a proposta de campanhas educativas para que a tarefa seja feita de forma a minimizar possíveis alterações e queixas de dor destes trabalhadores. 


\section{REFERÊNCIAS}

1- TEZZA, R. I. D. Predição computacional de promotores em Xanthomonas axonopodis pv. Citri. Trabalho de Conclusão de Curso (Graduação em Tecnóloga em Processamento de Dados) - Universidade Estadual Paulista, SÃO PAULO, 2008.

2- PASSOS, O. S; COELHO, S. Y; SOBRINHO, A. P. C. Variedades copa e porta-enxertos de citros. Aracajú - Se. 1977.

3- CORTEZ, L. A. B. et al. Sistemas de Colheita para Frutas e Hortaliças: oportunidades para sistemas semimecanizados. Revista Frutas \& Legumes, n. 22, p.26-29, 2002.

4- KROEMER, K. H. E.; GRANDJEAN, E. (Etienne). Manual de ergonomia : adaptando o trabalho ao homem . 5. ed. Porto Alegre: Bookman, 2008. 327p.

5- RODRIGUES, A. C. et al. Reestruturação e testes do protótipo de uma sacola coletora de citros utilizando a análise ergonômica do trabalho (AET) para a melhoria do processo de colheita. In: Anais do Simpósio Acadêmico de Engenharia de Produção (SAEPRO), 2008.

6 - IIDA, I. Ergonomia : projeto e produção. 2. ed. São Paulo: Edgard Blücher, 2010. 614p.

7- VERONESI, J. J. R. Fisioterapia do trabalho: cuidando da saúde funcional do trabalhador. São Paulo: Andreoli, 2008. 258p.

8- DUL, J; WEERDMEESTER, B. Ergonomia prática. 2. Ed. São Paulo: Edgard Blucher, 2004. 137p.

9- KENDALL, F. P. Músculos: provas e funções com postura e dor. 4. Ed. Barueri: Manole, 1995. 453p.

10 - PELLENZ, C. C. O. Indicadores de levantamento de carga e parâmetros mecânicos da coluna vertebral. 2005.

11- FANHANI, P.et AL. Importância da fisioterapia na prevenção de lesões no trabalho agríciola. . In: Anais do Congresso Paranaense de Fisioterapia, V, 29 e 30 de setembro e 01 de outubro, 2010.

OBSERVAÇÃO: Os autores declaram não existir conflitos de interesse de qualquer natureza. 